\title{
Preserved Performance by Cerebellar Patients on Tests of Word Generation, Discrimination Learning, and Attention
}

\author{
Laura L. Helmuth, Richard B. Ivry, ${ }^{1}$ and Naomi Shimizu \\ Department of Psychology \\ University of California \\ Berkeley, California 94720
}

\section{Abstract}

Recent theories suggest that the human cerebellum may contribute to the performance of cognitive tasks. We tested a group of adult patients with cerebellar damage attributable to stroke, tumor, or atrophy on four experiments involving verbal learning or attention shifting. In experiment 1 , a verb generation task, participants produced semantically related verbs when presented with a list of nouns. With successive blocks of practice responding to the same set of stimuli, both groups, including a subset of cerebellar patients with unilateral right hemisphere lesions, improved their response times. In experiment 2, a verbal discrimination task, participants learned by trial and error to pick the target words from a set of word pairs. When age was taken into account, there were no performance differences between cerebellar patients and control subjects. In experiment 3 , measures of spatial attention shifting were obtained under both exogenous and endogenous cueing conditions. Cerebellar patients and control subjects showed similar costs and benefits in both cueing conditions and at all SOAs. In experiment 4 , intra- and interdimensional shifts of nonspatial attention were elicited by presenting word cues before the appearance of a target. Performance was substantially similar for cerebellar patients and control subjects. These results are presented as a cautionary note. The experiments failed to provide

${ }^{1}$ Corresponding author. support for current hypotheses regarding the role of the cerebellum in verbal learning or attention. Alternative interpretations of previous results are discussed.

\section{Introduction}

The study of the cerebellum has emerged from the province of motor control. Although it remains clear that this subcortical structure has a prominent role in the coordination of movement, the last decade has seen an explosion of interest in nonmotor functions of the cerebellum. In a recent review, Fiez (1996) tracked this paradigm shift. Whereas the literature contained only an occasional reference to putative cognitive contributions of the cerebellum in the early 1980 s, more than 10 journal articles have appeared per year since 1990. Although this increase may, in part, reflect the proliferation of new journals, nonmotor functions of the cerebellum have captured center stage in both the popular press and at many major scientific conferences.

There are a number of factors motivating this trend. Careful anatomical studies have begun to reveal the organization of widespread inputs to the cerebellum, originating not only in sensorimotor cortex, but in many association and paralimbic cerebral areas as well (Schmahmann 1996). For example, using new labeling methods, Middleton and Strick (1994) uncovered projections to area 46 of prefrontal cortex in the cebus monkey from thalamic nuclei that are heavily innervated by the dentate nucleus of the cerebellum. Area 46 is anterior to the more traditional motor and premotor areas of frontal cortex, and is hypothesized to have a critical role in working memory (Goldman-Rakic 1992). The correlation between the development of prefrontal cortex in humans and the expansion

LEARNING \& MEMORY 3:456-474 CC 1997 by Cold Spring Harbor Laboratory Press ISSN1072-0502/97 \$5.00

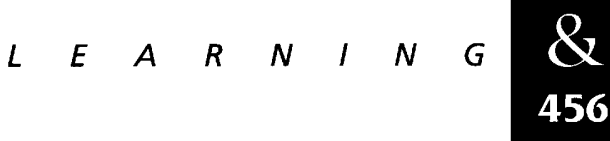


of the neocerebellum has inspired comparative anatomists to propose a functional relationship between these areas (Leiner et al. 1986, 1993). In addition, cerebellar pathology has been found to be a consistent marker of autism, a disorder that is marked by abnormal social, cognitive, and emotional development (for review, see Courchesne et al. 1994).

A second motivating factor has come from the neuroimaging literature. In a surprising number of studies, activation in the cerebellum is found even when the experimental and control conditions are equated in terms of the amount of overt movement. Cerebellar activation has been associated with a host of disparate tasks, including semantic generation (Petersen et al. 1989), problem solving (Kim et al. 1994), internal timing (Jueptner et al. 1995), and sensory exploration (Gao et al. 1996). The functional bases of these activation results remain unclear. One hypothesis has been that the cerebellum is a critical component of an internal rehearsal process (Awh et al. 1996; Fiez et al. 1996; but see Ivry 1997).

The anatomical and imaging studies do not, by themselves, mandate a radical reinterpretation of cerebellar function. As shown by a number of imaging studies, processes associated with the preparation or imagination of movements involve many of the same mechanisms as those used in the actual production of movement (e.g., Roland et al. 1980; Decety et al. 1994; Ryding et al. 1993). The cerebellar activation in these studies may still be best construed as related to motor control, but reflecting covert motor processes (Ivry 1997). According to this view, the functional links between the cerebellum and prefrontal cortex may point to weaknesses with traditional divisions of frontal cortex into "motor" and "cognitive" regions.

On the other hand, some provocative neuropsychological findings are difficult to reconcile with even an expanded definition of motor function. Patients with lesions of the cerebellum have been reported to be impaired on a variety of nonmotor tasks such as time perception (Ivry and Keele 1989), velocity perception (Ivry and Diener 1991; Nawrot and Rizzo 1995), mental fluency (Appollonio et al. 1993), attention shifting (Courchesne et al. 1994), and associative learning (Bracke-Tolkmitt et al. 1989; Canavan et al. 1994). In these studies the motor requirements are minimal and the dependent variables involve psychophysical thresholds or accuracy measures.

The development of functional hypotheses to account for these deficits is still in its infancy. It remains to be seen whether mechanistic explanations will offer a unified account of these deficits or whether it will be necessary to posit a more heterogeneous view of cerebellar function. Ivry and his colleagues have argued that the cerebellum has a special role in the internal representation of temporal information (for review, see Ivry 1993). By this hypothesis, the cerebellar timing system will be invoked whenever a task, motoric or nonmotoric, requires this form of representation. Whereas this hypothesis can account for some of the neuropsychological results, it does not seem sufficient to account for deficits on more conceptual tasks.

Other nonmotor hypotheses have sought to provide a more general view of cerebellar function. Some of these are rather generic, arguing by analogy that the cerebellum in humans is essential for mental coordination (Leiner et al. 1986), with dysfunction in this system producing mental dysmetria or ataxia (Schmahmann 1996). How this coordination is achieved remains to be specified. Part of the problem to date has been a lack of convergence across the imaging and neuropsychological studies, both in terms of the theoretical underpinnings and in terms of methodology. Moreover, the neuropsychological literature has proven inconsistent. In addition to the positive findings noted above regarding nonmotor impairments following cerebellar lesions, other researchers have reported null results on both standard neuropsychological assessments (e.g., Berent et al. 1990) as well as on experiments designed to explore focused cognitive domains. In one well-designed and thorough study reported by Daum et al. (1993), patients with lesions restricted to the cerebellum were unimpaired on tests of frontal lobe function, memory, and perceptual and conceptual skill acquisition.

In this report we test two nonmotor hypotheses concerning the role of the cerebellum in cognition. Experiments 1 and 2 were designed to investigate the hypothesis that the role of the cerebellum in covert rehearsal is critical for verbal fluency and learning (Fiez et al. 1996). Experiments 3 and 4 address the proposal put forth by Courchesne and colleagues (e.g., Courchesne et al. 1994) regarding a critical function for the cerebellum in the rapid deployment of covert attention. Previous neuropsychological tests of these hypotheses have relied on either case studies (Akshoomoff et al. 1992; Fiez et al. 1992) or group designs primarily involving autistic children or pa-

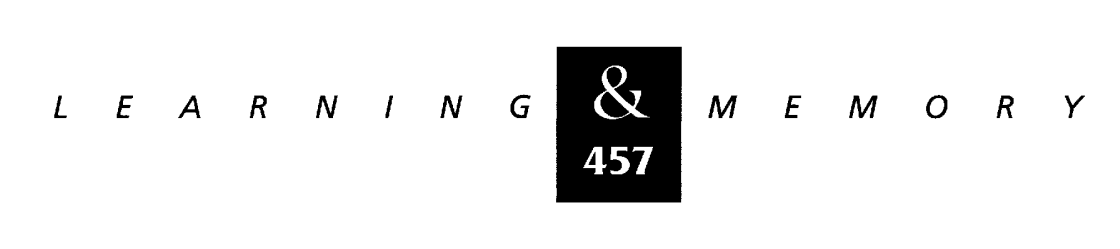


Helmuth et al.

tients with childhood cerebellar disorders (Courchesne et al. 1994; Townsend et al. 1996a,b). In the following four experiments, we compare the performance of adult patients with cerebellar lesions to age-matched control groups. By using a group design with adult subjects, we can explore the generality of previous findings as a means for evaluating the merits of these two hypotheses.

\section{PARTICIPANTS}

A total of 12 patients with confirmed lesions of the cerebellum were tested. These patients were recruited through the Neurology Department at the Veterans Administration Medical Center in Martinez, CA. Patients were selected based on clinical reports and neuroimaging evidence confirming pathology in the cerebellum. Table 1 presents the age at the time of testing, etiology of the cerebellar disorder, the duration of the disorder, and an overall assessment of the severity of their motor disorders. Three patients suffered from bilateral cerebellar atrophy, resulting either from chronic alcoholism (case 12) or unidentified factors (cases 10 and 11). In the former case, the magnetic resonance image (MRI) revealed atrophy restricted to the anterior lobe; in the latter cases, degeneration was extensive in the cerebellar hemispheres and extended into brainstem structures (olivopontocerebellar atrophy).
For the other nine patients, the lesions were the result of strokes $(n=6)$ or tumors $(n=3)$, and were generally restricted to a single half of the cerebellum. Figure 1 presents reconstructions of these focal lesions, drawn on a set of horizontal templates. The reconstructions were done by a neurologist who was unaware of the experimental hypotheses being tested. With one exception, the patients were also given a clinical exam that included tests of posture, gait, eye movements, and volitional movements with the upper and lower extremities. Their motor symptoms ranged from mild to severe.

The final column in Table 1 lists the experiments each patient participated in. The data were collected over a 3-year period, and some patients were only available for a single session.

Control subjects for experiments 1 and 2 were recruited from the Martinez Veterans Administration Medical Center. Four control subjects participated in experiment 1 , ranging in age from 54 to 76 years $($ mean age $=62.8$, s.D. $=9.4$ ). Three additional subjects participated in experiment 2 , for a total of seven control subjects, with the same age range and a mean age of 62.6 (s.D. $=7.0)$. Control subjects for experiments 3 and 4 were recruited from the North Berkeley Senior Center. Twelve subjects participated in experiment 4, ranging in age from 55 to 78 years (mean age $=71$, s.D. $=7.5$ ). Eleven of these 12 control subjects participated in

Table 1: Summary information for the group of cerebellar patients

\begin{tabular}{|c|c|c|c|c|c|}
\hline $\begin{array}{l}\text { Code } \\
\text { number }\end{array}$ & Age & Type of cerebellar damage & $\begin{array}{c}\text { Motor } \\
\text { assessment }^{\mathrm{a}}\end{array}$ & $\begin{array}{c}\text { Time since damage } \\
\text { (years) }\end{array}$ & $\begin{array}{c}\text { Experiments } \\
\text { participated in }\end{array}$ \\
\hline 01 & 57 & right hemisphere stroke & 4 & 4 & 2 \\
\hline 02 & 74 & right hemisphere tumor resected & 3 & 10 & 3,4 \\
\hline 03 & 67 & right hemisphere stroke & 1 & 5 & $1,2,3,4$ \\
\hline 04 & 47 & right hemisphere stroke & - & 3 & 1,2 \\
\hline 05 & 52 & right hemisphere stroke & 2 & 9 & $1,2,3,4$ \\
\hline 06 & 70 & right hemisphere tumor resected & 1 & 29 & $1,2,3$ \\
\hline 07 & 74 & left hemisphere stroke & 2 & 3 & $1,2,3,4$ \\
\hline 08 & 49 & left hemisphere tumor resected & 3 & 10 & $1,2,3,4$ \\
\hline 09 & 73 & left hemisphere stroke & 2 & 4 & $1,2,3,4$ \\
\hline 10 & 68 & $\mathrm{OPCA}^{\mathrm{c}}$ & 5 & 5 & $2,3,4$ \\
\hline 11 & 72 & $\mathrm{OPCA}^{\mathrm{c}}$ & 5 & 32 & $1,2,3,4$ \\
\hline 12 & 62 & vermal atrophy & 2 & 0 & $1,2,4$ \\
\hline
\end{tabular}

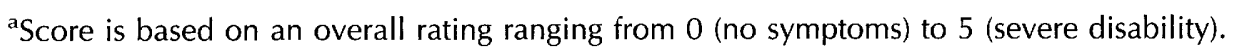

${ }^{b}$ Case 12 was tested shortly after diagnosis of alcohol-related cerebellar atrophy, but he, like the other atrophy patients, is likely to have been symptomatic prior to his diagnosis.

${ }^{c}$ Olivopontocerebellar atrophy.

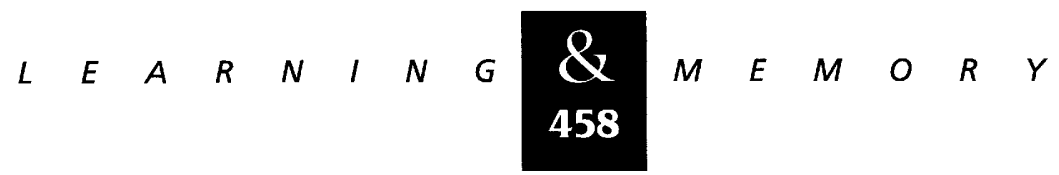




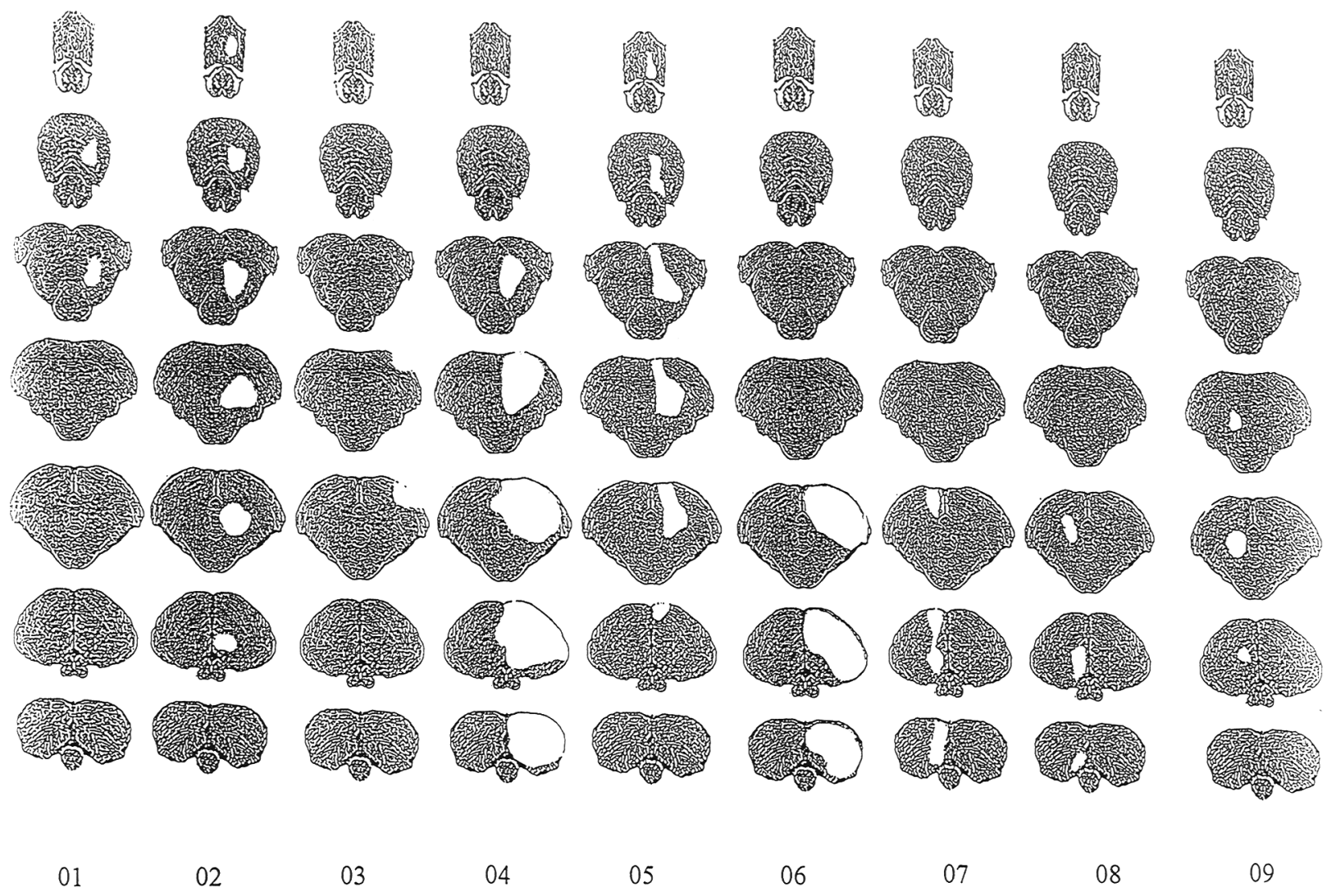

Figure 1: Lesion reconstructions for the nine patients with unilateral, focal lesions. The dentate nucleus is prominent in the fourth and fifth slices from the top. Based on this, cases 02, 04, 05, and 09 likely have dentate involvement. The extent of dentate damage is unclear for cases 06 and 08 .

experiment 3 (mean age $=70.5$, s.D. $=7.7$ ). All control subjects reported no history of neurological or psychiatric disorders.

\section{Experiment 1: Semantic Generation}

As noted above, Fiez and her colleagues have proposed a role for the cerebellum in covert rehearsal (Fiez et al. 1996). Internal rehearsal and the sustained representation of verbal information would be expected to be essential for many tasks. For example, the semantic associate task introduced by Petersen et al. (1989) requires subjects to generate a semantically associated verb in response to a target noun. Selection of an appropriate response might require that all of the candidate responses be sustained in a working memory system. Similarly, many conceptual learning tasks require the internal maintenance of verbal knowledge. Although the imaging studies suggest that the cerebellum is part of this rehearsal system, they do not indicate whether this structure's contribution is essential for such tasks. The cerebellum might have a role in preparing potential responses, but the essential representations might exist outside the cerebellum.

A case study reported by Fiez et al. (1992) speaks to this issue. This patient, RC1, had a large focal lesion of the right cerebellar hemisphere. On standard neuropsychological measures, the patient's intellect appeared intact. His score on the Wechsler Adult Intelligence Scale was in the superior range (131), and he had no difficulty on various memory and naming tasks. Nonetheless, compared with control subjects, RC1 was severely impaired on a series of tasks of semantic association. Following the method of Petersen et al. (1989), he and three control subjects were presented with a list of 40 nouns. For each noun, they were to generate a verb associate as rapidly as possible (e.g., razor-shave). Unlike the control subjects, the patient frequently responded with semantic associ-

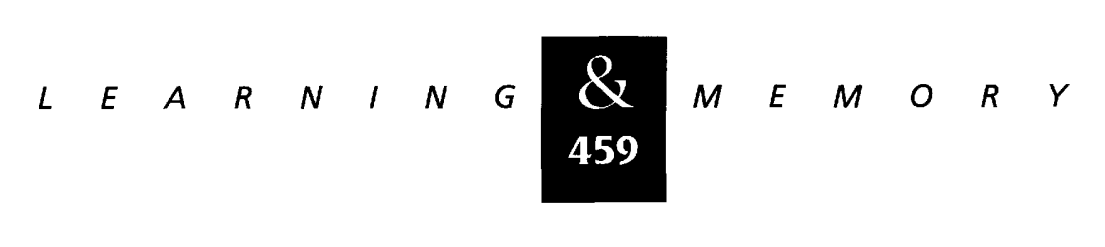


ates from the wrong class. For example, to the words razor and dog, he responded sharp and cat, respectively. Moreover, when tested over repeated blocks, RC1 failed to show a decrease in reaction time. This failure to show evidence of learning is consistent with the imaging results of Raichle et al. (1994). In this study cerebellar activation was prominent on blocks of unfamiliar nouns, but the activation diminished over successive blocks. Because subjects tend to use the same semantic associates over blocks, the task changes from one of semantic generation to retrieval. The failure of the patient to show a decrease in reaction time (RT) was taken as evidence that verbal retrieval and learning is associated with the cerebellum.

Given that this case study is cited widely, it seemed appropriate to investigate whether a similar deficit could be replicated in a group of cerebellar patients.

\section{Materials and Methods}

The set of stimulus words was the same as that used in the Fiez et al. (1992) study. The set consisted of 40 common, concrete nouns, three to seven letters in length. Letters were $2 \mathrm{~cm}$ high, or $\sim 2.3^{\circ}$ of visual angle, and on average, $5.7^{\circ}$ of visual angle wide. The words appeared in white on a black background.

Each participant was tested individually. The participant was seated in front of a computer screen and asked to watch the screen as words appeared. The experimenter informed the participant that his or her goal should be to respond as quickly as possible, saying the first verb that came to mind that was related to the stimulus words, The experimenter assured participants that the test was one of semantic knowledge, and not a personality test.

Each stimulus word was presented at the center of the screen. A voice-activated relay was not available, so the actual reaction times were recorded in the following manner: The experimenter rested her hand on the response board, facing away from the computer screen. When the participant initiated a response, she pressed the response key. Reaction times were measured from the time the word appeared on the screen to the time the response key was depressed. Therefore, the reaction times reported include the time necessary for the experimenter to push the response key, a duration of $-300 \mathrm{msec}$. [The experimenter was not blind to the group status (i.e., patient or control) of each subject, but did not have any a priori expectations regarding group differences; therefore bias is unlikely to have been a problem. We recorded the verbs spoken by some of the patients. However, it soon became apparent that the participants, both patients and controls, made very few errors, and that these data would not be informative.]

The stimulus word disappeared from the screen once the response key was pressed. It was replaced by a plus symbol and subjects were asked to maintain fixation on this marker. After a delay of $1500 \mathrm{msec}$, the next stimulus appeared.

The stimulus words were presented in blocks of 20 nouns. A short rest was provided between each block. During blocks 1 through 5, the training blocks, the same 20 nouns were presented in each block, in a randomized order. In block 6 , the transfer block, a new set of 20 nouns was presented. Stimuli were counterbalanced between subjects, with some participants responding to list A during blocks 1-5 and list B during block 6 , and vice-versa for other participants. Ten words, none of which were used in the experiment, were used in an initial practice block.

\section{Results and Discussion}

The median reaction times were calculated for each subject in each block. These values were averaged by group and are plotted in Figure 2. Over the five training blocks, both the patients and control subjects showed a significant decrease in reaction time, $F(4,11)=17.4, P<0.001$, and the group by block interaction was not significant, $F(4,11)<1.0$. Furthermore, the increase in reaction time on the transfer block was significant, $F(1,11)=13.9, P<0.005$, but did not differ between the two groups $F(1,11)=1.0, P=0.33$.

As shown by the larger standard error bars in Figure 2, there was considerably greater betweensubject variability in the patient group, resulting from the fact that some of the patients had difficulty in initiating verbal responses. For example, the difference between the fastest and slowest patient on block 5 was 2413 msec; the comparable value for the control group was $380 \mathrm{msec}$. The possibility arises that the large between-subject variability may have obscured deficits in individual patients, a concern given that we are emphasizing null results. However, all of the cerebellar patients

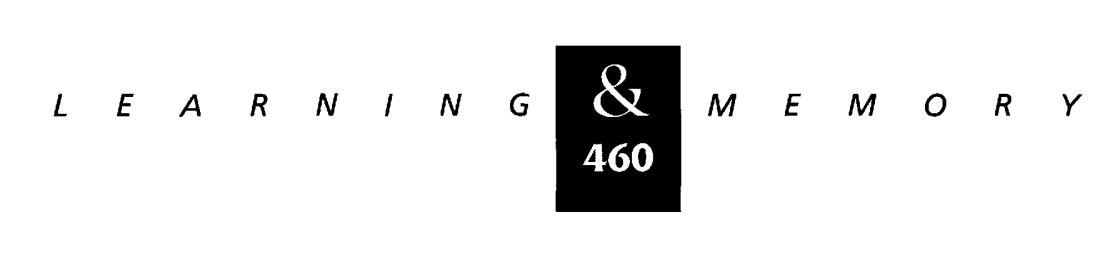




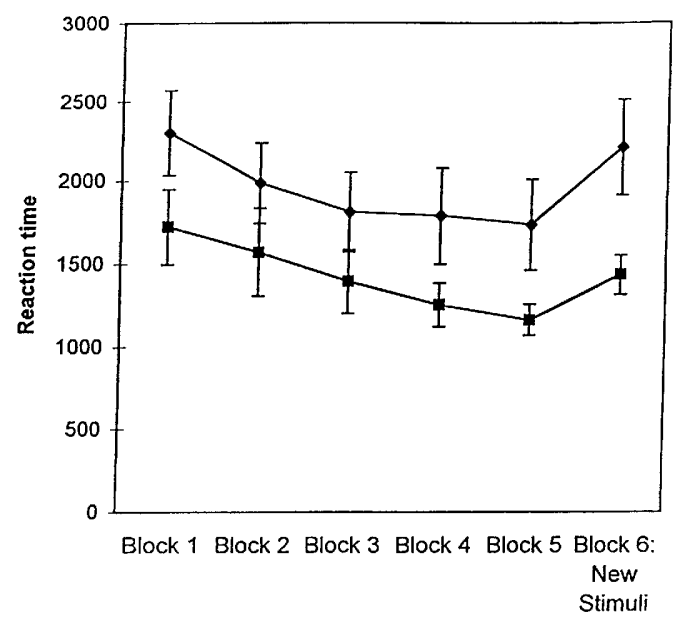

Figure 2: Mean reaction times for cerebellar patients $(\bullet)$ and control subjects ( $\square$ ) producing semantically associated verbs to visually presented nouns. Error bars indicate standard errors. During blocks $1-5$, the same set of 20 target nouns was used. During block 6, a new set of nouns was presented.

showed evidence of learning on this task. (Table 2).

Previous research has suggested that the right cerebellar hemisphere may be particularly involved in the verb generation task. Position emission tomography (PET) studies have revealed activation in the right cerebellar hemisphere in normal subjects performing the verb generation task (Petersen et al. 1989; Raichle et al. 1994), and patient RC1's lesion was also on this side (Fiez et al. 1992). A subset of four of the patients participating in experiment 1 had right-sided cerebellar damage, including case 4 and case 6 , who had lesions very similar to those of RC1. The results for the right hemisphere focal lesion group was quite similar to those observed for the entire group. Over the training blocks, the mean reaction time for the right hemisphere $(\mathrm{RH})$ group decreased by over 600 msec, $F(4,3)=8.6, P<0.005$, and increased on the transfer block by $>400$ msec, $F(1,3)=8.5$, $P=0.06$. Case 4 decreased response time from a median $1484 \mathrm{msec}$ in the first block to $1163 \mathrm{msec}$ in the fifth block, and responded with a median latency of $1203 \mathrm{msec}$ in the transfer block. Case 6 improved performance over the course of the five training blocks from $1925 \mathrm{msec}$ to $1318 \mathrm{msec}$. In the transfer block, the median reaction time of case 6 was 2062 msec.

In summary, the results of experiment 1 fail to support the hypothesis that the cerebellum is essential for the retrieval of category-specific seman- tic associates or the learning of item-specific semantic associates. Not only did the patients show learning on the semantic associate task, but the extent of learning was equivalent to that observed for the control subjects. This equivalence was observed in both the learning curve during the training blocks and in the transfer measures. These null findings were also evident when the analyses were restricted to patients with focal lesions of the right cerebellar hemisphere.

\section{Experiment 2: Verbal Discrimination Learning}

Fiez et al. (1992) report a second experiment showing a verbal learning deficit in patient $\mathrm{RC} 1$. In their verbal learning discrimination task, subjects are presented with a series of 20 word pairs. Through feedback, they must learn which member has been arbitrarily designated the target. The pairs are repeated on successive blocks. After 20 training blocks, control subjects are essentially perfect at this task. They almost always choose the target member of each pair. In contrast, patient RC1 remained at chance over the 20 training blocks. Fiez et al. (1992) propose that the cerebellum operates as an error detection system, not only in the more traditional motor sphere (e.g., Marr 1969; Gilbert and Thach 1977), but also in cognition. According to this interpretation, RC1's deficit resulted from a failure to use information regarding the correct status of his choices from block to block.

We attempted to replicate this finding in our group of cerebellar patients.

\section{Materials and Methods}

The stimulus set consisted of 20 word pairs. We used the same words as had been used in the Fiez et al. (1992) study. Each word was a concrete noun. The letters were the same size as in experiment 1 .

Participants in this experiment were seated in front of a computer screen in a quiet room. The experimenter explained that word pairs would appear on the screen, and that the participant's task was to learn which word from each word pair was the "correct" word. Participants were told that there was no reason for one word or the other to be correct, and that they should try to find out, by trial and error, which word was correct. The ex-

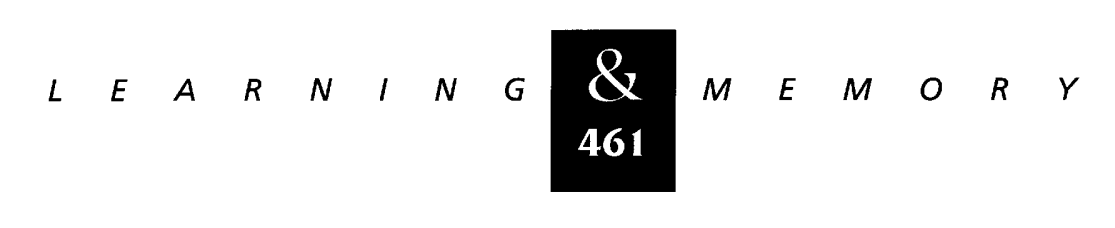


Helmuth et al.

Table 2: Individual subjects' performances in experiments 1 and 2

\begin{tabular}{|c|c|c|c|c|c|}
\hline \multicolumn{3}{|c|}{ Experiment 1} & \multicolumn{3}{|c|}{ Experiment 2} \\
\hline $\begin{array}{l}\text { cerebellar } \\
\text { patient }\end{array}$ & $\begin{array}{l}\text { block } 1-5 \\
\text { (RT in msec) }\end{array}$ & $\begin{array}{c}\text { block } 6-5 \\
\text { (RT in msec) }\end{array}$ & $\begin{array}{l}\text { cerebellar } \\
\text { patient }\end{array}$ & age & $\begin{array}{c}\text { average percent } \\
\text { correct on last } 3 \text { blocks }\end{array}$ \\
\hline 03 & 1199 & 470 & 01 & 57 & 95.0 \\
\hline 04 & 321 & 40 & 03 & 67 & 41.7 \\
\hline 05 & 385 & 440 & 04 & 47 & 86.7 \\
\hline 06 & 607 & 744 & 05 & 52 & 86.7 \\
\hline 07 & 1270 & 377 & 06 & 70 & 81.7 \\
\hline 08 & 451 & 13 & 07 & 74 & 61.7 \\
\hline 09 & 204 & 1311 & 08 & 49 & 86.7 \\
\hline 11 & 329 & 489 & 09 & 73 & 58.3 \\
\hline \multirow[t]{3}{*}{12} & 372 & 404 & 10 & 68 & 56.7 \\
\hline & & & 11 & 72 & 43.3 \\
\hline & & & 12 & 62 & 81.7 \\
\hline Mean & 570.9 & 476.4 & Mean & 62.8 & 70.9 \\
\hline S.D. & 391.9 & 385.7 & S.D. & 10.0 & 19.0 \\
\hline $\begin{array}{l}\text { Control } \\
\text { subject }\end{array}$ & & & $\begin{array}{l}\text { Control } \\
\text { subject }\end{array}$ & & \\
\hline 01 & 201 & 320 & 01 & 60 & 88.3 \\
\hline 02 & 715 & 393 & 02 & 61 & 70.0 \\
\hline 03 & 441 & 168 & 03 & 54 & 96.7 \\
\hline \multirow[t]{4}{*}{06} & 897 & 204 & 04 & 66 & 91.7 \\
\hline & & & 05 & 63 & 65.0 \\
\hline & & & 06 & 76 & 58.3 \\
\hline & & & 07 & 58 & 86.7 \\
\hline Mean & 563.5 & 271.3 & Mean & 62.6 & 79.5 \\
\hline S.D. & 305.8 & 103.9 & S.D. & 7.0 & 14.8 \\
\hline
\end{tabular}

perimenter explained that the participant could only guess one of the words at first, but that there would be feedback on the screen after each response, indicating if the choice was correct or incorrect. The participants were told that the set of 20 word pairs would then appear repeatedly, but in a random order and with the locations of the words within the pair randomized. They were instructed to use what they had learned on previous blocks to help them guess which word was correct when they saw the word pair again.

On each trial, a word pair was presented, with the two words positioned one above a plus sign and the other below the plus sign. The locations for the two words within a pair was determined randomly for each trial. Participants responded by pressing one of two keys on a response board. They were told to press one key if they thought that the word on the top was correct, and to press the other key if they thought that the word on the bottom was correct. The participants were informed that accuracy was important and speeded responses were discouraged. Immediately after a response was made, feedback was displayed on the computer screen. In the center of the screen, either the word "CORRECT" or the word "INCORRECT" appeared in red letters. The feedback remained on the screen for $1 \mathrm{sec}$. After a 1-sec intertrial interval, the next word pair appeared on the screen.

After each block of 20 word pairs, performance for that block was summarized on the screen, providing a second source of feedback. The percent correct for the block appeared on the screen, and the experimenter explained that this number referred to the percent of the word pairs

$$
\text { …..... 道 }
$$


that the subject had responded to correctly. The next block began after the participants indicated they were ready. For each block, the order of the word pairs as well as the locations of the words within a pair was randomized. Testing continued in this manner for 10 blocks.

\section{Results and Discussion}

Performance on this task was highly variable. A number of the cerebellar patients and control subjects quickly learned to discriminate the word pairs. Cerebellar case 01 responded correctly to 95\% of the word pairs after just four blocks of practice. Cerebellar case 03 , however, as well as one of the control subjects, performed at chance levels on the discrimination learning task even after 10 repetitions of the set of word pairs.

Figure 3 presents the mean percent correct for the cerebellar patients and the control subjects. To reduce the noise in the data sets, we have averaged performance over successive pairs of blocks. In the statistical analysis, each block was treated as a repeated measure. This analysis revealed that the patients did show a learning deficit in comparison with the control subjects. Whereas there was no overall difference in performance, the group by block interaction was significant, $F(9,16)=2.3$, $P<0.025$. As can be seen in Figure 3, although the groups are similar at the beginning of learning, the

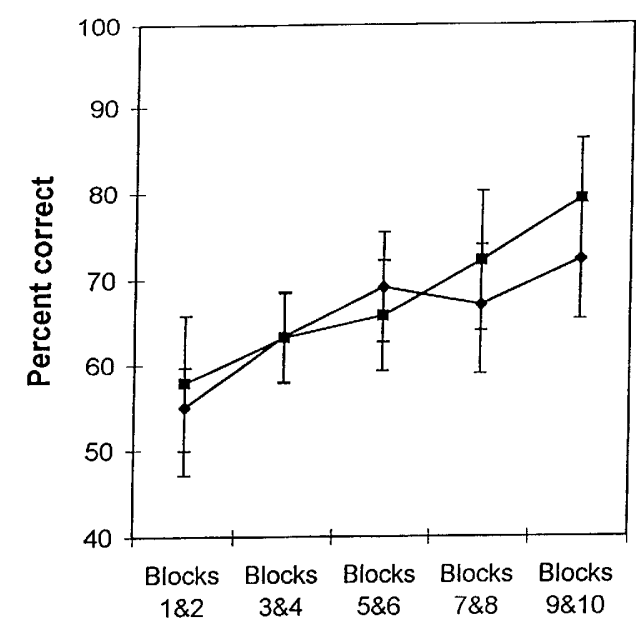

Figure 3: Mean percent correct for cerebellar patients $(\downarrow)$ and control subjects ( $\boldsymbol{\square}$ ) on successive blocks of a word discrimination task. Error bars indicate standard errors. For clarity, the data have been combined over pairs of blocks. Probability is $50 \%$. control subjects reach a higher level of performance by the end of the experiment.

Although these results would suggest a verbal learning deficit in the patients, further analyses revealed that a third variable had an important part in the results. The percent correct over the last three blocks for each participant is shown in the last column of Table 2 . As can be seen here, a good predictor of performance on this task appears to be age. This relationship holds for both the patients and controls. The correlation between age and the average performance on the last three blocks of the experiment was -0.70 for all participants. This variable was a strong predictor for both the patients $(-0.73)$ and the control subjects $(-0.70)$. When age is included as a covariate in the analysis, the difference between the two groups disappeared completely, $F(1,15)<1$. Although there was no significant difference in age between the two groups, $t(16)=0.75, P>0.25$, the patients tested on this task tended to be older than the control subjects. Five of the patients were in their 70s. In contrast, only one of the control subjects was in his 70s, and his performance was below the mean for the group, reaching only $58 \%$ correct on the final three blocks. The younger patients had little difficulty in learning the verbal discriminations.

The fact that our groups were not better matched in terms of age requires that these data be interpreted with caution. The analysis of covariance may have removed additional sources of variance unrelated to age, including possible effects related to cerebellar damage. Nonetheless, it is reasonable to expect age to have a role in this task. The verbal discrimination learning task requires the coordination of many cognitive abilities. Participants have to remember which word was chosen on previous trials, and whether the feedback from that choice had been positive or negative. They have to process feedback and link it to the response just made, to use that information on subsequent trials. They have to avoid developing a bias for the incorrect word. Randomization of the order of presentation of the pairs as well as randomization of the relative positions of the words on successive trials prevents the use of sequence or location cues. Sustained attention is required, as there can be interference from previous trials and responses. It is not surprising that some older subjects, even those with no known neurological damage, fail to learn the arbitrary categorization of the word pairs.

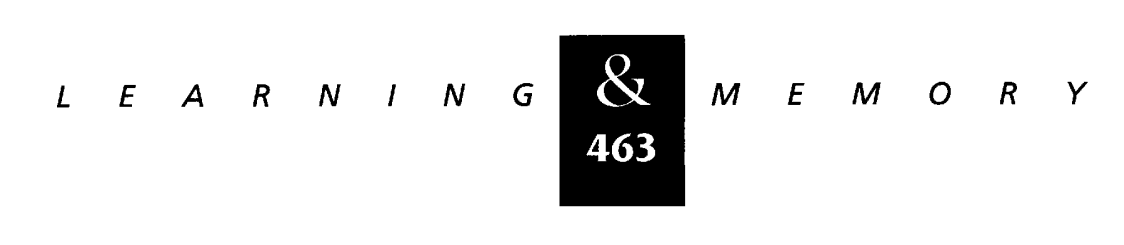


To summarize, our results diverge from those reported in the case study of Fiez et al. (1992). Although the patients did not learn the verbal discriminations as well as the control subjects, this apparent deficit was accounted for by the fact that the cerebellar group included more older subjects than the control group. Age cannot account for the poor performance of RC1 in the Fiez et al. (1992) study. He was 49 years old at the time of testing. We do not have an explanation for his poor performance on this task, a result that is even more surprising considering his elevated IQ. Nonetheless, the current results suggest that cerebellar damage, per se, does not predict performance on this verbal discrimination task.

\section{Experiment 3: Rapid Shifts of Spatial Attention}

E. Courchesne and his colleagues have developed a novel functional hypothesis concerning the role of the cerebellum in cognition (see Courchesne et al. 1994). They propose that the cerebellum has a principal role in the rapid deployment of attentional resources. According to this hypothesis, the cerebellum is viewed as part of an attentional network, contributing to the speed with which attentional resources can be activated. This idea provides one instantiation of the conjecture that the cerebellum is involved in mental coordination. Coordinating rapid shifts of covert attention has been argued to be a generalization of the cerebellum's motor control function for coordinating rapid, skilled movement.

This hypothesis originates in E. Courchesne's research on autism. As discussed in the Introduction, cerebellar pathology is a consistent marker of autism (see Courchesne and Allen 1997), with the majority of cases involving cerebellar hypoplasia. Attentional abnormalities including deficits in distribution and shifting of the focus of attention have been considered a component of the autistic syndrome in many theories (e.g., Courchesne 1987; Frith and Baron-Cohen 1987). For example, the autistic individual is frequently observed to be overly fixated on a particular object or action. Behavioral and event-related potential (ERP) evidence consistent with this idea have been reported by Townsend and Courchesne (1994), including the finding that autistic individuals may be better than normal subjects at attending to a cued location. Of course, normal behavior requires that we achieve a balance between attending to current relevant events while being ready to shift our focus to potentially important, novel stimuli (for a comparative perspective, see Paulin, 1993).

Courchesne and his colleagues have employed a variety of attention tasks to test the validity of this hypothesis. One task requires subjects to monitor a stream of visual and auditory events. Within each modality, there are two types of stimuli-a low frequency, target stimulus, and a high frequency, distractor stimulus. In a focused attention condition, the subjects must respond to targets within a single dimension. For example, if the attended dimension is color, they respond to all of the infrequent red stimuli while ignoring the blue stimuli and all of the tones. In a divided attention condition, the subjects alternate between the two dimensions. Each time they respond to a target on one dimension, they must shift to the other dimension and begin monitoring for the target from the other dimension. Both autistic individuals (Akshoomoff and Courchesne 1992) and children with cerebellar abnormalities (Courchesne et al. 1994) show a selective impairment on the divided attention condition. Moreover, their problem is not a general inability to shift attention, it is limited to those situations in which two targets appear in rapid succession. If the second target appears after a substantial delay, the patients' performance is comparable with that of age-matched control subjects. These findings are in accord with the hypothesis that the cerebellum does not control the allocation of attention, but rather facilitates the rapid deployment of attentional resources.

Although these early studies suggested a special role of the cerebellum in shifting between dimensions, more recent evidence indicates that the problem is also manifest in rapid intradimensional shifts (Akshoomoff and Courchesne 1994; Townsend et al. 1996a,b). Townsend et al. $(1996 a, b)$ used a spatial orienting task developed by Posner (1980). In this task, subjects are instructed to press a button whenever they detect a target stimulus. Before the onset of the target, a cue appears, either at the target location (valid condition) or a position in the opposite visual field (invalid condition). By varying the interval between the cue and target (the stimulus-onset asynchrony, or SOA), measures can be obtained of the relative speed of attentional orienting. Townsend et al. (1996a,b) found that the autistic individuals were slow to respond to valid targets when the SOA was only $100 \mathrm{msec}$. With the 800-msec SOA,

$$
\text { w...... }
$$


the autistic individuals were as fast as the control subjects. Even more striking, these RT effects were mirrored in a second task in which accuracy was measured using a second, identification task (Townsend 1996b; task 2).

Except for two children with unilateral cerebellar lesions, the cerebellar groups in the Townsend et al. studies were composed of people with autism. In this study we tested our adult group of patients with cerebellar disorders on a similar spatial orienting task. [Although it would be preferable to have used identical procedures to that of Townsend et al. (1996a,b), these studies were initiated independently, hence, the great differences in methodology.]

\section{Materials and Methods}

A plus sign was visible throughout a block of trials. It was positioned at the center of the display and served as a fixation point. Two boxes flanked the fixation marker, one to the left and one to the right. The sides of the boxes were $\sim 4.0^{\circ}$ in visual angle per side, and were centered $8.0^{\circ}$ from the fixation point. Participants were told that an $\mathrm{X}$ would appear at various times in one of the boxes, and that they should press the response key as soon as possible after they detected the $\mathrm{X}$ (the target) in either box. All responses were made by pressing the response board with the preferred index finger (dominant hand for control subjects and patients with atrophy; contralesional hand for patients with unilateral cerebellar lesions). Note that this is a simple reaction time task; the subjects did not have to indicate the location of the $\mathrm{X}$.

Two different conditions were tested, exogenous cueing and endogenous cueing. In the exogenous condition, one of the boxes brightened before the target appeared. This peripheral cue did not predict whether a target $\mathrm{X}$ would appear in that location. The exogenous cue appeared on the same side as the target on $50 \%$ of the trials (valid condition) and on the nontarget side on the other $50 \%$ of the trials (invalid condition). The onset of the cue was followed by the target after a delay of either 50, 150, or $300 \mathrm{msec}$. The cue and target remained on until the subject responded. The next trial began 1200 msec after the subject's response. Subjects were told that the cue would not be informative. However, previous research with nonpredictive cues has shown that reaction times are faster to valid targets compared with invalid targets (Posner 1980).
In the endogenous condition, the center fixation cross was replaced by an arrow pointing to one side or the other. The arrow cue was valid, pointing to the location where the target later occurred, on $70 \%$ of the trials. For the other $30 \%$ of the trials, the target appeared at the opposite location. As in the exogenous condition, the target followed the onset of the cue by either 50,150, or $300 \mathrm{msec}$. In this condition, the subjects were told that the cue was predictive of the target location and that they could use this information to respond more quickly to the target.

The endogenous and exogenous conditions were presented in separate blocks. Each subject completed two blocks of 150 trials each of the endogenous condition and one block of 120 trials of the exogenous condition. The exogenous block was always run between the two endogeneous blocks.

\section{Results and Discussion}

Attentional orienting and shifting can be assessed in a few different ways with this task. One measure focuses on the validity effect, the difference between the median reaction times required to respond to valid and invalid targets. Figure 4 presents the validity effect for the cerebellar patients and control subjects in both the exogenous and endogenous conditions. As can be seen, a robust validity effect was obtained in both conditions, which grows in magnitude with SOA. For the exogenous condition, valid trials were faster than invalid trials by $42 \mathrm{msec}, F(1,18)=33.6$, $P<0.0001$ and the interaction of validity and SOA approaches significance, $F(2,36)=2.45, P=0.10$. For the endogenous condition, valid trials were faster by $72 \mathrm{msec}, F(1,18)=75.6, P<0.0001$ and the interaction was significant, $F(2,36)=4.35$, $P<0.05$. Therefore, both types of cues were effective in orienting attention.

Most importantly for our present concerns, there was no interaction between group and the size of the validity effect [exogenous: $F(1,18)=1.27$, $P=0.27$; endogenous, $F(1,18)<1]$. Although the cerebellar patients appear to have a slightly lower validity effect than controls in the exogenous condition at shorter SOAs (Fig. 4), the -jthree-way interaction of SOA, validity, and group does not approach significance, $F(2,18)<1$. A post-hoc comparison of the validity effect at just

$$
\text { ,....... }
$$




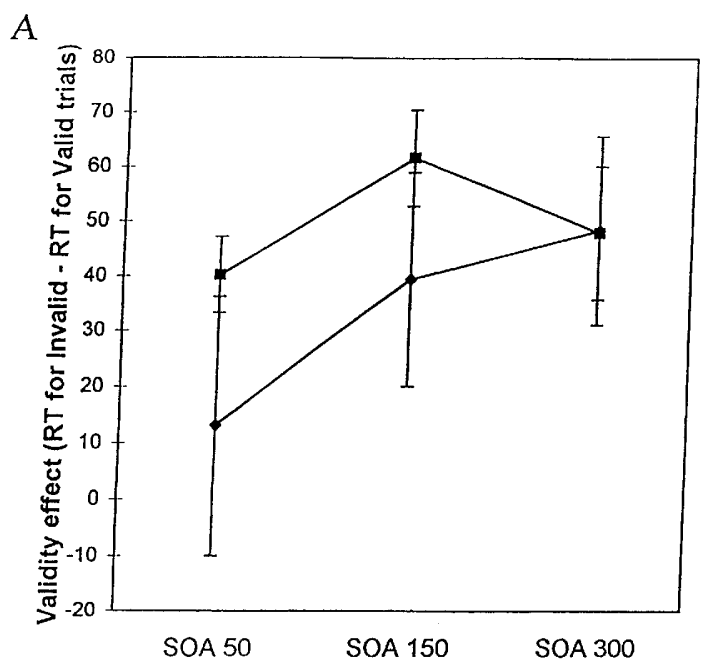

B

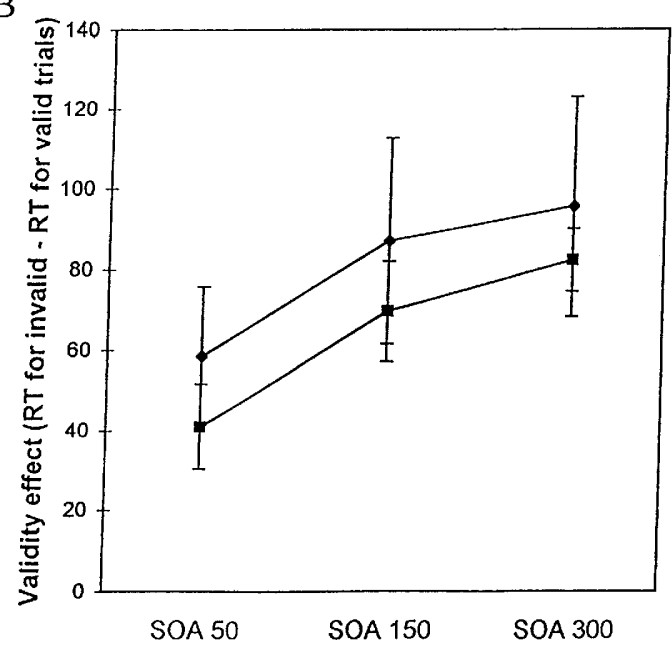

Figure 4: Validity effects for cerebellar patients $(\bullet)$ and control subjects ( $\mathbf{\square}$ ) on the spatial cueing task. Plotted are the differences between reaction times following invalid cues minus reaction times following valid cues, for three different SOAs. Error bars indicate standard errors. $(A)$ Exogenous cueing condition. (B) Endogenous cueing condition.

the shortest SOA, $50 \mathrm{msec}$, also revealed no group difference, $\quad F(1,18)=2.52, \quad P=0.13$. Individual subjects' validity scores in the exogenous cueing condition are presented for both cerebellar patients and control subjects in Table 3 . Note that the relatively small validity effect at the shortest SOA for the cerebellar group is attributable to one patient with an extreme outlying score. If this patient is excluded, the mean validity effects for the cerebellar group are 34,50 , and 54 msec for the 50-, 150-, and 300-msec SOAs, respectively.
Townsend et al. (1996a,b) have also reported that, with two exceptions, the validity effect is comparable for autistic individuals and control subjects. The first exception is when the analysis is restricted to autistic individuals with MRI evidence of both cerebellar and parietal lobe damage (Townsend et al. 1996a). These individuals show an enhanced validity effect, a result that is consistent with previous studies of neurological patients with unilateral parietal lobe damage (e.g., Posner et al. 1984).

The second exception is reported in Townsend et al. (1996b), a study that tested autistic individuals with MRI evidence showing only cerebellar pathology. In this study the group by validity effect was significant. However, the interaction does not appear to reflect an enhanced validity effect for the autistic individuals, a result one might expect if they have a problem in shifting attention. Rather, it appears to be attributable to the fact that the control subjects failed to show a validity effect in the $800-\mathrm{msec}$ SOA condition. At this SOA, the control subjects were equally fast responding to the valid and invalid trials. The lack of a validity effect for the control subjects should be treated cautiously. First, Townsend et al. (1996a) failed to replicate this finding. In this experiment, the control subjects showed a validity effect of $\sim 11 \%$ at both the 100- and 800 -msec SOAs, and this value was not statistically different from that observed in the autistic individuals. Second, other studies using a very similar procedure and SOAs have found that the validity effect is maintained at SOAs of 800 msec (e.g., Posner et al. 1988).

Seven of the cerebellar patients participating in Experiment 3 suffered from unilateral cerebellar lesions. Four of these patients had right-sided lesions; three had left-sided lesions. To assess whether performance was differentially affected by the side of presentation, we compared the reaction times of these patients for targets presented in the ipsilesional and contralesional hemifields. No effects of target side were observed in the endogenous cueing condition. However, in the exogenous cueing condition, the three-way interaction of validity, side of presentation, and SOA was significant, $F(2,12)=4.0, P<0.05$. Although the validity effect was comparable for the two sides at the two shortest SOAs, there was a difference at the 300-msec SOA. For these trials, the validity effect was $62 \mathrm{msec}$ when the target appeared in the contralesional (e.g., good) hemifield and only 4

$$
\text { ........ 圆"..... }
$$


Table 3: Individual subjects' performances in experiments 3 and 4

\begin{tabular}{|c|c|c|c|c|c|c|c|c|}
\hline \multicolumn{5}{|c|}{ Experiment 3 (exogenous condition) } & \multicolumn{4}{|c|}{ Experiment 4} \\
\hline \multirow[b]{2}{*}{$\begin{array}{l}\text { cerebellar } \\
\text { patient }\end{array}$} & \multicolumn{4}{|c|}{ validity score (msec) } & \multirow[b]{2}{*}{$\begin{array}{c}\text { cerebellar } \\
\text { patient }\end{array}$} & \multicolumn{3}{|c|}{ validity score (msec) } \\
\hline & $\begin{array}{c}\text { SOA } \\
50\end{array}$ & $\begin{array}{l}\text { SOA } \\
150\end{array}$ & $\begin{array}{c}\text { SOA } \\
300\end{array}$ & $\begin{array}{l}\text { RT to valid } \\
\text { trials at } \\
\text { SOA } 50- \\
\text { SOA } 300\end{array}$ & & $\begin{array}{l}\text { category } \\
\text { cue }\end{array}$ & $\begin{array}{l}\text { element } \\
\text { cue, } \\
\text { same } \\
\text { category }\end{array}$ & $\begin{array}{c}\text { element } \\
\text { cue, } \\
\text { different } \\
\text { category }\end{array}$ \\
\hline 02 & 46 & 12 & 21 & 12 & 02 & 62 & 183 & 191 \\
\hline 03 & 41 & 41 & 36 & 47 & 03 & 45 & -15 & 7 \\
\hline 05 & -5 & 84 & 12 & 99 & 05 & -27 & 206 & 215 \\
\hline 06 & 47 & -32 & 30 & 63 & 07 & -1 & 214 & 233 \\
\hline 07 & 24 & 121 & 120 & 81 & 08 & 3 & 639 & 488 \\
\hline 08 & 15 & 49 & 113 & 91 & 09 & 81 & 152 & 143 \\
\hline 09 & 52 & 74 & -1 & 8 & 00 & 36 & 101 & 176 \\
\hline 10 & 51 & 55 & 99 & 116 & 11 & 46 & 203 & 166 \\
\hline 11 & -153 & -50 & 3 & -23 & 12 & 20 & 180 & 243 \\
\hline Mean & 13.1 & 39.3 & 48.1 & 54.9 & Mean & 30.5 & 204.1 & 206.4 \\
\hline S.D. & 65.2 & 54.8 & 48.6 & 47.3 & S.D. & 32.1 & 167.4 & 119.3 \\
\hline $\begin{array}{l}\text { Control } \\
\text { subject }\end{array}$ & & & & & $\begin{array}{l}\text { Control } \\
\text { subject }\end{array}$ & & & \\
\hline 01 & 26 & 94 & 40 & 27 & 01 & 36 & 142 & 193 \\
\hline 02 & 47 & 70 & 150 & 49 & 02 & 174 & 194 & 498 \\
\hline 03 & 57 & 57 & 68 & 5 & 03 & 189 & 129 & 199 \\
\hline 04 & 49 & 53 & 15 & 17 & 04 & 90 & 60 & 101 \\
\hline 05 & 62 & 78 & 43 & 37 & 05 & -49 & 96 & 192 \\
\hline 06 & 35 & 60 & 58 & 26 & 06 & -4 & 71 & 119 \\
\hline 07 & 50 & 10 & 32 & 0 & 07 & 217 & 275 & 324 \\
\hline 08 & 8 & 61 & 49 & 32 & 08 & -4 & 50 & 52 \\
\hline 09 & 70 & 92 & 6 & 78 & 09 & 133 & 118 & 193 \\
\hline 10 & -2 & 86 & 28 & 42 & 10 & 33 & 127 & 181 \\
\hline 12 & 40 & 14 & 35 & 75 & 11 & 189 & 164 & 323 \\
\hline & & & & & 12 & 22 & 117 & 181 \\
\hline Mean & 40.2 & 61.4 & 47.6 & 35.3 & Mean & 85.5 & 128.6 & 213 \\
\hline S.D. & 22.2 & 28.2 & 38.3 & 25.1 & S.D. & 91.5 & 62.3 & 119.3 \\
\hline
\end{tabular}

msec when the target appeared in the ipsilesional (e.g., bad) hemifield.

A second measure of attentional orienting is given by how quickly the cues influence the subjects' performance. As noted in the introduction to this experiment, Townsend et al. (1996a,b) reported that the autistic individuals were slower than control subjects in responding to valid targets, but only at the 100 -msec SOA. In the current experiment, the patients with cerebellar lesions tended to respond more slowly than the control subjects [exogenous: $F(1,18)=2.17, P=0.16$; en- dogenous: $F(1,18)=7.27, P<0.05]$. This effect interacted with SOA in the endogenous condition only, $F(2,36)=3.37, P<0.05$, and the three-way interaction of Group, Validity, and SOA did not approach significance. Similar to the results of Townsend et al. (1996a,b), we found that the difference in reaction time between the cerebellar patients and control subjects was most pronounced at the shortest SOA, at least in the endogenous condition (Fig. 5). Quite possibly, this effect would have become even more pronounced if we had extended our range of SOAs.

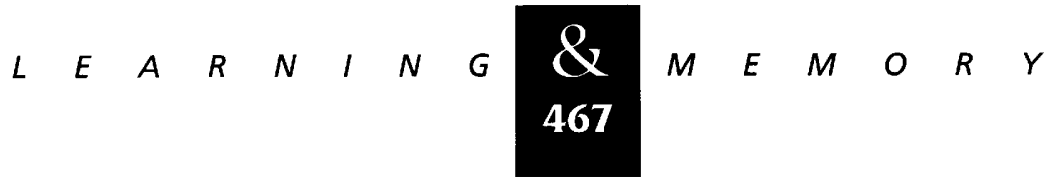




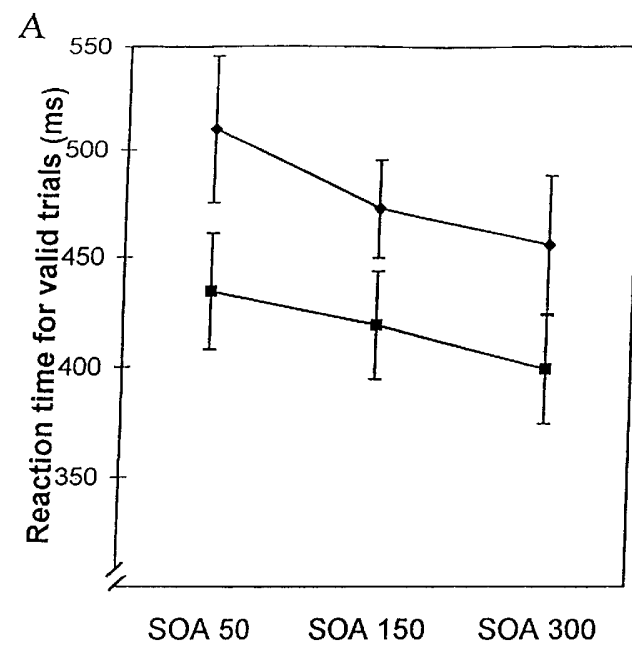

B

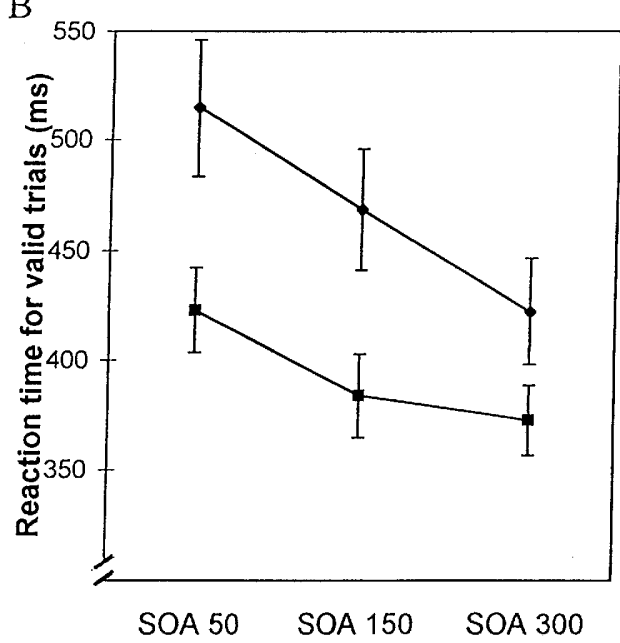

Figure 5: Mean reaction times for cerebellar patients $(\checkmark)$ and control subjects $(\boldsymbol{\square})$ to validly cued targets as a function of SOA. Error bars indicate standard errors. $(A)$ Exogenous cueing condition. $(B)$ Endogenous cueing condition:

Nonetheless, it is difficult to infer an attentional deficit based on the slower RTs of the cerebellar group at the shortest SOAs. Cerebellar lesions are known to increase simple reaction time (Meyer-Lohmann et al. 1977; Spidalieri et al. 1983). Whereas the mechanisms for this increase remain unclear, it is possible that, with longer SOAs, the patients could begin some of the preparation required to initiate a response. Control subjects also become faster as the SOA is lengthened, presumably because their expectancy for the target increases (see Gottsdanker et al. 1986).

At present, it is premature to draw any firm conclusions regarding the role of the cerebellum in spatial orienting. Based on the hypothesis that cer- ebellar pathology reduces the speed with which attention can be oriented, one would predict that the validity effect would be reduced at short SOAs. This is the pattern observed by Rafal et al. (1988) in a study of patients with damage to the superior colliculus. In contrast, the results of our study and Townsend et al. (1996a,b) offer little evidence that the cerebellum is essential for rapid shifts of attention based on the magnitude of the validity effect. In these studies, autistic individuals with pathology restricted to the cerebellum show normal validity effects. This is similar to what we observed in the current group of patients with acquired cerebellar lesions, although we did observe one difference in our within-subject analysis involving the patients with unilateral lesions.

On the other hand, there is evidence of a relative slowness in responding at short SOAs. Although this result might be attributable to differences in motor preparation, there remains the provocative result of Townsend et al. (1996b) on an identification task. In this task, the letter E served as the target and subjects judged its orientation (e.g., facing left, facing up, etc.). As in the basic orienting task, the $\mathrm{E}$ was presented in one of two peripheral boxes and was preceded by either a valid, neutral, or invalid cue. Autistic individuals were very poor in reporting the orientation of the E, especially at the shortest SOA. Because only accuracy was emphasized, it does not seem reasonable to attribute this deficit to a problem in motor preparation. It would be interesting to see if a similar problem would be found in our patient group.

\section{Experiment 4: Intra- and Interdimensional Shifting of Attention}

Posner and his colleagues (Posner and Petersen 1990) have suggested that there is a hierarchical organization of attentional systems. A spatial attention system is specialized for directing attention in external space, allowing us to shift our focus from one location or object to another. This system is distributed across a number of cortical and subcortical neural structures, with the cortical system including parietal and frontal eye field regions. Frontal areas, including anterior cingulate and dorsolateral prefrontal cortex, have been linked with nonspatial aspects of attentional control including the selection and shifting of attentional set (e.g., Corbetta et al. 1993). Many PET studies (Awh et al. 1996; Fiez et al. 1996) have

$$
\ldots . . . .6
$$


found correlated activation patterns in prefrontal cortex and cerebellum, suggesting that these areas in concert might form a higher level attentional network.

As noted previously, individuals with cerebellar pathology, either associated with autism or from neurological episodes, have been found to perform poorly on a task requiring rapid shifts in attentional set (Akshoomoff and Courchesne 1992, 1994; Courchesne et al. 1994). This task involved shifts between attending to color and pitch, two nonspatial attributes of a stimulus stream. In experiment 4 , we introduce a new task designed to assess attentional shifts on a nonspatial task. Unlike the continuous nature of the attention shifting task introduced by Akshoomoff and Courchesne (1992), we adopted a discrete trial method. In this way, we employed the logic of the cueing methodology that has guided much of the work on spatial attention.

\section{Materials and Methods}

There were four target stimuli in this experiment, two colors and two shapes. The colors, red or blue, were presented as filled circles (diameter of $2.9^{\circ}$ visual angle). The shapes, square and triangle, were presented as filled, black shapes $\left(\sim 2.9^{\circ}\right.$ visual angle).

Participants were asked to respond as quickly as possible to the targets. Responses were made on one of two response keys according to a 4:2 stimulus-response mapping. The red circle and black square were assigned to one response key and the blue circle and black triangle were assigned to the other response key. All responses were made with the subject's preferred hand, either the dominant hand for the control subjects or the least affected for the patients.

On each trial, the target was preceded by a cue, a word appearing at the center of the screen. Subjects were told that the cues would usually allow them to anticipate the forthcoming target, and therefore reduce their response latencies. There were seven different cues: one neutral cue, two category cues, and four element cues. For the neutral condition, the word any was used as the cue. For the category conditions, either the word color or shape was used as the cue. For the element conditions, the words red, blue, square, or triangle were used as cues. The cues, ranging in size from $3.4-6.9^{\circ}$ visual angle, were displayed in the center of the screen for $350 \mathrm{msec}$. The screen then went blank for $250 \mathrm{msec}$, followed by the stimulus. After the subject responded to the stimulus, the screen went blank for $1000 \mathrm{msec}$ before the onset of the next cue.

The neutral cue was presented on $34 \%$ of the trials, category cues on $23 \%$ of the trials, and element cues on $43 \%$ of the trials. For the category and element conditions, the cue was valid on $70 \%$ of the trials and invalid on $30 \%$ of the trials. When a category cue was valid, the target was one of the two stimuli from the cued dimension (e.g., the word color was followed by either the red or blue circle). For invalid category cues, the target was one of the stimuli from the uncued dimension (e.g., the word color was followed by either the black square or black triangle). Similarly, element cues indicated the exact target on $70 \%$ of the trials. On the invalid element trials, the target could either be from the cued dimension (e.g., the word red followed by a blue circle) or from the other dimension (e.g., the word red followed by a black square).

The participants were first tested on a practice block of 76 trials. Feedback was provided during the practice block. If a subject pressed the incorrect key, both an auditory signal (a series of beeps) and a visual message (KEYPRESS WAS IN ERROR) indicated that an error had been made. Following the practice block, the participants completed a single test block of 360 trials. Short breaks were provided during this block.

\section{Results and Discussion}

Median reaction times were calculated for each subject for each of the cueing conditions and averaged together to create group means. The invalid element trials can be further subdivided into trials in which the target was from the same category as the cue and trials in which the target was from the other category. The reaction time data are shown in Figure 6.

As is found in most reaction time experiments, the cerebellar patients were slower overall to respond to the targets, $F(1,20)=23.6, P<0.001$. A more relevant analysis of the data focuses on relative costs and benefits. Both the control subjects and cerebellar patients were faster on valid trials compared to neutral trials. For the category cue condition, this difference was $30 \mathrm{msec}$,

$$
\ldots . . . \cdots
$$




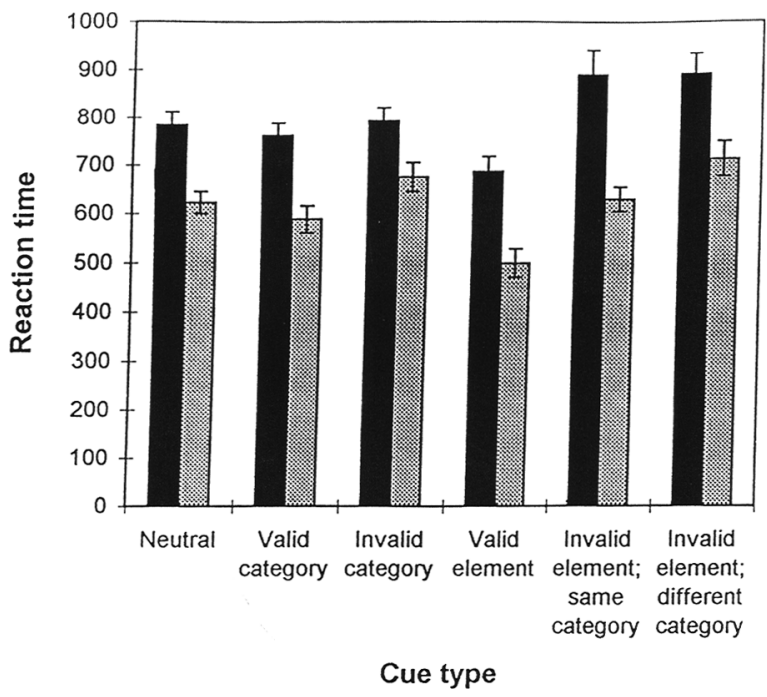

Figure 6: Mean reaction times for cerebellar patients (solid bars) and control subjects (shaded bars) to targets in six different cueing conditions (see text). Error bars indicate standard errors.

$F(1,20)=10.6, P<0.01$; for the element cue condition, the effect was $114 \mathrm{msec}, F(1,20)=49.4$, $P<0.001$. There were no differences between the two groups on either of these measures. The fact that the groups were faster on these trials indicates that they were able to rapidly shift their attention in anticipation of the target stimuli.

A second measure of attention shifting is given by comparing the valid and invalid trials. In these conditions, the subjects prepare for one target (element cue) or set of targets (category cue), but then must alter their attentional set when the target appears. In general, the effects on invalid trials were similar for the patients and control subjects. Responses were slower on invalid trials compared to valid trials following both category cues, $F(1,19)=12.74, \quad P<0.01$, and element cues, $F(1,19)=6.75, P<0.02$.

There were, however, two differences between the two groups. For the category condition, the cost on invalid trials for the control subjects compared with the patients approached significance, $F(1,19)=3.03, P<0.10$. For the element condition, the cerebellar patients showed an equal cost when the invalid target was in the same dimension as when it was in the other dimension (207 msec in both conditions). For the control subjects, the between dimension cost was greater (213 msec compared with $128 \mathrm{msec}$ for a withindimension invalid target). The group by invalid tar- get type interaction was significant, $F(1,19)=6.79$, $P<0.02$.

Individual subjects' validity scores for category cues and element cues from both the same and different dimensions are presented in Table 3 . Validity scores are calculated by subtracting the median reaction time to validly cued responses from the median reaction time to invalidly cued responses. Notice that none of the cerebellar patients shows a particularly large category cueing effect (>100 msec), whereas five of the control subjects do. Similarly, within the element cue conditions, the patients show little difference in cost when the target is from the same dimension as the cue compared with when the target is from the different dimension. In contrast, 11 of the 12 controls show a cost that is at least $40 \mathrm{msec}$ greater when the invalid cue is from a different dimension than the stimulus.

At present, the interpretation of these results remains open. On the one hand, the results suggest that the cerebellar patients were less able to use category information compared with the control subjects. Therefore, they showed a reduced category cueing effect and showed comparable validity effects for the two types of invalid element cues. One interpretation would be that the patients tended to treat the four stimuli as independent items rather than organize them into two, two-element categories. On the other hand, the patients were able to benefit from the valid category and element cues, and the magnitude of these benefits were comparable with those observed with the control subjects. In the two places where group differences were observed, the costs of shifting attention could be seen as being in opposite directions. On invalid category trials, the patients showed a smaller cost than the controls, suggesting a failure to use the category cues. However, on invalid element trials, the patients showed comparable costs as the controls when shifting between categories. The primary difference here was that they showed a larger cost on the invalid, same category trials.

It is difficult to reconcile these results with the hypothesis of a deficit in shifting attention. First, the overall pattern is quite similar between the patients and control subjects. Second, a shifting account of the few differences does not appear parsimonious. One might argue that the reduced category effect results from a failure of the patients to orient to the cued category. However, such an account would also predict that the patients would

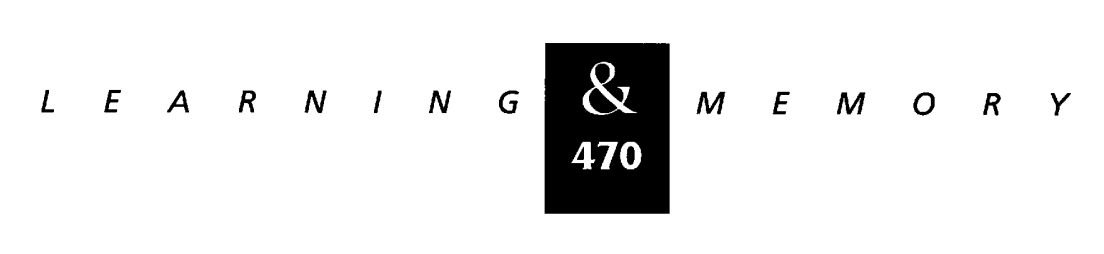


show a reduced element cueing effect, and that this might be most marked on the invalid element, different category condition. This was not the case.

\section{Conclusions}

Cognitive neuroscience has evoked a paradigm shift in cerebellar research. This shift has been fueled by new findings in the areas of neuroanatomy, neuropsychology, and neuroimaging. At present, the development and assessment of functional hypotheses regarding nonmotor functions of the cerebellum is clearly just beginning. The results reported in this paper offer a cautionary note as we develop new theories about the role of the cerebellum in cognition. In all four experiments, we failed to find consistent deficits in a group of adult patients with cerebellar lesions on a variety of cognitive tasks.

The first two experiments were essentially replications of tasks that had been used by Fiez et al. (1992). In this widely cited case report, a patient with a large, unilateral cerebellar lesion was observed to have severe deficits on a variety of linguistic and nonlinguistic cognitive tasks. We chose to focus on two tasks from the Fiez et al. (1992) study, semantic generation and verbal learning. The former task has been studied extensively in PET studies, and consistently shows activation in the cerebellum (Petersen et al. 1989; Raichle et al. 1994). Although it is difficult to make functional inferences about computation from neuroimaging studies, the learning task had been used to test the idea that the cerebellum has a generic role in feedback-based learning, an idea that is well-grounded in the motor learning literature.

Contrary to the case study of Fiez et al. (1992), we failed to find consistent learning deficits on these two tasks in our group of patients with cerebellar lesions. Not only were the patients able to generate semantic associates, but they showed a normal learning function on this task. The patients did perform more poorly than the control subjects on the verbal discrimination task, but the deficit here appears to be primarily a function of age.

It remains unclear how to reconcile the present results with those of Fiez et al. (1992). An obvious question is whether there is a difference in terms of the loci of cerebellar pathology. Whereas our patients constituted a heterogeneous group, there was a subset of patients with lesions similar to those of the Fiez et al. (1992) patient, encompassing at least the inferior half of the right cer- ebellar hemisphere. Analyses restricted to this group also failed to provide evidence of a replication. At present, the most conservative conclusion seems to be that the case study represented an exception rather than the rule. The utility of case studies has been heatedly debated in the neuropsychological literature (see Caramazza and McCloskey 1988; Robertson et al. 1993). It is clear that case studies can open new avenues of inquiry. However, there are clear limitations with the single patient approach, especially in terms of linking function with structure. The function-structure issue is especially problematic with the Fiez et al. (1992) patient given the lack of an autopsy following his sudden death at age 50 . It remains possible that his neuropathology was not limited to the cerebellum.

Our final two experiments were designed to test the hypothesis that the cerebellum is essential for the rapid deployment of attention (Courchesne and Allen 1997). There are at least two appealing features of this hypothesis. First, it offers a relatively specific functional hypothesis regarding how the cerebellum might contribute to cognition, and the area of attention shifting has been widely studied in both psychology and the neurosciences. Second, the hypothesis is motivated, in part, by considering how nonmotor functions of the cerebellum might have developed from a more narrow functional domain. Similar to how the cerebellum is essential for coordinating rapid movements, E. Courchesne and colleagues have looked for a way in which this structure might help coordinate cognition.

Nonetheless, experiments 3 and 4 fail to support the attention shifting hypothesis. As a group, the patients were slower in responding on the spatial and nonspatial reaction time tasks. But analyses designed to focus on the speed of attentional deployment did not reveal a selective deficit in the patients compared with age-matched control subjects, except in conditions in which the deficits might be attributed to a problem in making speeded responses. Moreover, similar to Townsend et al. (1996a,b), our group of patients tended to show comparable reaction time differences between valid and invalid cues.

It is difficult to make direct comparisons between our studies and those reported by E. Courchesne and colleagues (1994; Akshoomoff and Courchesne 1992, 1994; Townsend et al. 1996a,b). Our group consists entirely of patients who acquired cerebellar disorders as adults. In the Cour-

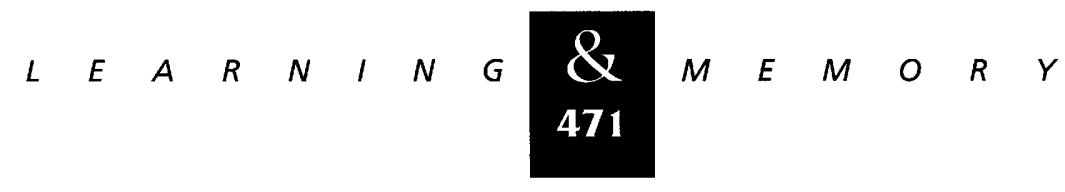


chesne studies, autistic individuals have generally been used as a model for cerebellar dysfunction, bolstered by corresponding studies using adolescents with acquired cerebellar lesions. The onset age of cerebellar dysfunction is certainly different between the two groups. In addition, the tasks reported in this paper are not identical to those employed in Courchesne's laboratory.

Our intent is not to dismiss the basic idea that the best characterization of cerebellar function extends beyond the domain of motor control. In other work we have proposed that the cerebellum operates as a generalized internal timing system, invoked in both motor and nonmotor tasks that require precise timing (see Ivry 1993). Moreover, there remains a number of provocative results that require explanation. First, a number of studies have reported frontal-like symptoms in patients with cerebellar lesions (Bracke-Tolkmitt et al. 1989; Appollonio et al. 1993; Canavan et al. 1994; but see Daum et al. 1993). Second, autistic individuals as well as patients with acquired cerebellar lesions have been found to perform poorly on attention tasks using accuracy measures rather than reaction time (Akshoomoff and Courchesne 1992; Courchesne et al. 1994; Townsend et al. 1996b). Third, neuroimaging studies continue to reveal cerebellar activation even when the motor requirements are equated in control and experimental conditions (see Fiez 1996).

At present, it is difficult to offer a unified account of these findings. What is clear is that it is important that we consider and test conservative, simple hypotheses before we adopt complex explanations. For example, the deficits shown on accuracy measures generally involve tasks that require the production of successive, rapid responses. It may be that people with cerebellar dysfunction have to monitor their responses, and therefore have less resources available for subsequent stimuli. This interpretation would, of course, shift the emphasis back toward an essentially motoric problem. Similarly, Ivry (1997) has suggested that the cerebellar activation in the imaging studies may reflect the preparation of multiple responses. Whether such preparation is best construed as "cognitive" remains to be seen.

\section{Acknowledgments}

This research was supported by the National Institutes of Health (NS30256 and NS17778). We are grateful to Robert Knight, Robert Rafal, and Donatella Scabini for their assistance in identifying and evaluating the patients. Julie Fiez kindly provided us with the MRI scans for patient RC1, as well as the stimulus lists used in experiments 1 and 2 .

The publication costs of this article were defrayed in part by payment of page charges. This article must therefore be hereby marked "advertisement" in accordance with 18 USC section 1734 solely to indicate this fact.

\section{References}

Akshoomoff, N.A. and E. Courchesne. 1994. ERP evidence for a shifting attention deficit in patients with damage to the cerebellum. J. Cognitive Neurosci. 6: 388-399.

1992. A new role of the cerebellum in cognitive operations. Behav. Neurosci. 106: 731-738.

Akshoomoff, N.A., E. Courchesne, G.A. Press, and V. Iragui. 1992. Contribution of the cerebellum to neuropsychological functioning: evidence from a case of cerebellar degenerative disorder. Neuropsychologia 30: 315-328.

Appollonio, I.M., J. Grafman, V. Schwartz, S. Massaquoi, and M. Hallett. 1993. Memory in patients with cerebellar degeneration. Neurology 43: 1536-1544.

Awh, E., J. Jonides, E.E. Smith, E.H. Schumacher, R.A. Koeppe, and S. Katz. 1996. Dissociation of storage and rehearsal in verbal working memory: Evidence from positron emission tomography. Psychol. Sci. 7: 25-31.

Berent, S., B. Giordani, S. Gilman, L. Junck, S. Lehtinen, D.S. Markel, M. Bolvin, K.J. Kluin, R. Parks, and R.A. Koeppe. 1990. Neuropsychological changes in olivopontocerebellar atrophy. Arch. Neurol. 47: 997-1001.

Bracke-Tolkmitt, R., A. Linden, A.G.M. Canavan, B. Rockstroh, E. Scholz, K. Wessel, and H.-C. Diener. 1989. The cerebellum contributes to mental skills. Behav. Neurosci. 103: $442-446$.

Canavan, A.G., R. Sprengelmeyer, H.C. Diener, and V. Homberg. 1994. Conditional associative learning is impaired in cerebellar disease in humans. Behav. Neurosci. 108: 475-485.

Caramazza, A. and M. McCloskey. 1988. The case for single-patient studies. Special issue: Methodological problems in cognitive neuropsychology. Cognit. Neuropsychol. 5: $517-527$.

Corbetta, M., F.M. Miezin, G.L. Shulman, and S.E. Petersen. 1993. A PET study of visuospatial attention. J. Neurosci. 13: $1202-1226$.

Courchesne, E. 1987. A neurophysiological view of autism. In Neurobiological issues in autism (ed. E Schopler and G.B. Mesibov), Plenum, New York.

Courchesne E. and G. Allen. 1997. Prediction and preparation, fundamental functions of the cerebellum. Learn. $\&$ Mem. (in press)

Courchesne, E., J. Townsend, and O. Saitoh. 1994. The brain in infantile autism: Posterior fossa structures are abnormal. Neurology 44: 214-223.

Courchesne, E., J. Townsend, N.A. Akshoomoff, O. Saitoh, R.

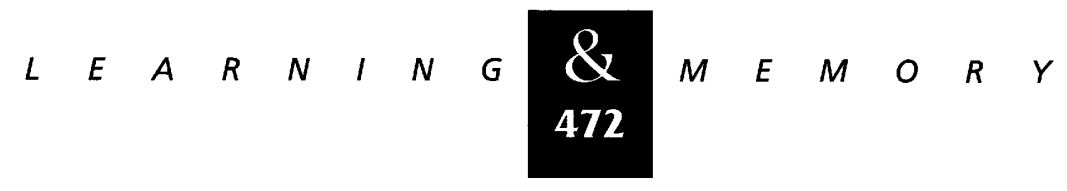


Yeung-Courchesne, A.J. Lincoln, H.E. James, R.H. Haas, H.E. Schreibman, and L. Lau. 1994. Impairment in shifting attention in autistic and cerebellar patients. Behav. Neurosci. 108: 848-865.

Daum, I., H. Ackermann, M.M. Schugens, C. Reimold, J. Dichgans, and N. Birbaumer. 1993. The cerebellum and cognitive functions in humans. Behav. Neurosci. 107: 411-419.

Decety, J., D. Perani, M. Jeannerod, V. Bettinardi, B. Tadary, R. Woods, J.C. Mazziotta, and F. Fazio. 1994. Mapping motor representations with positron emission tomography. Nature 371: 600-602.

Fiez, J.A. 1996. Cerebellar contributions to cognition. Neuron 16: 13-15.

Fiez, J.A., S.E. Petersen, M.K. Cheney, and M.E. Raichle. 1992. Impaired non-motor learning and error detection associated with cerebellar damage. A single case study. Brain 115: 155-178.

Fiez, J.A., M.E. Raichle, D.A. Balota, P. Tallal, and S.E. Petersen. 1996. PET activation of posterior temporal regions during auditory word presentation and verb generation. Cerebr. Cortex. 6: 1-10.

Frith, U. and S. Baron-Cohen. 1987. Perception in autistic children. In Handbook of autism and pervasive developmental disorders (ed. D.J. Cohen and A.M. Donnellan), pp. 85-102. Wiley, New York.

Gao, J.H., L.M. Parsons, J.M. Bower, J. Xiong, J. Li, and P.T. Fox. 1996. Cerebellum implicated in sensory acquisition and discrimination rather than motor control. Science 272: 545-547.

Gilbert, P.F.C. and W.T. Thach. 1977. Purkinje cell activity during motor learning. Brain Res. 128: 309-328.

Goldman-Rakic, P.S. 1992. Working memory and the mind. Sci. Am. 267: 111-117.

Gottsdanker, R., T. Perkins, and J. Aftab. 1986. Studying reaction time with nonaging intervals: An effective procedure. Behav. Res. Methods, Instr. \& Comp. 18: 287292.

Ivry, R. 1993. Cerebellar involvement in the explicit representation of temporal information. Ann. N.Y. Acad. Sci. 682: $214-230$.

1997. The many manifestations of a cerebellar timing system. In The cerebellum and cognition (ed. J. Schmahmann), Academic Press, New York. (In press).

Ivry, R. and H.C. Diener. 1991. Impaired velocity perception in patients with lesions of the cerebellum. J. Cognit. Neurosci. 3: 355-366.

Ivry, R. and S. Keele. 1989. Timing functions of the cerebellum. J. Cognit. Neurosci. 1: 136-152.
Jueptner, M., M. Rijntjes, C. Weiller, J.H. Faiss, D. Timmann, S.P. Mueller, and H.C. Diener. 1995. Localization of a cerebellar timing process using PET. Neurology 45: 1540-1545.

Kim, S.G., K. Ugurbil, and P.L. Strick. 1994. Activation of a cerebellar output nucleus during cognitive processing. Science 265: 949-951.

Leiner, H.C., A.L. Leiner, and R.S. Dow. 1986. Does the cerebellum contribute to mental skills? Behav. Neurosci. 100: $443-454$.

1993. Cognitive and language functions of the human cerebellum. Trends Neurosci. 16: 444-447.

Marr, D. 1969. A theory of cerebellar cortex. J. Physiol. 202: $437-470$.

Meyer-Lohmann, J., J. Hore, and V.B. Brooks. 1977. Cerebellar participation in generation of prompt arm movements. J. Neurophysiol. 40: 1038-1050.

Middleton, F.A. and P.L. Strick. 1994. Anatomical evidence for cerebellar and basal ganglia involvement in higher cognitive function. Science 266: 458-461.

Nawrot, M. and M. Rizzo. 1995. Motion perception deficits from midline cerebellar lesions in human. Vision Res. 35: $723-731$.

Paulin, M.G. 1993. The role of the cerebellum in motor control and perception. Brain Behav. Evol. 41: 39-50.

Petersen, S.E., P.T. Fox, M.I. Posner, M. Mintun, and M.E. Raichle. 1989. Positron emission tomographic studies of the processing of single words. J. Cognit. Neurosci. 1: 153-170.

Posner, M.I. 1980. Orienting of attention. The VII Sir Frederic Bartlett lecture. Quart. J. Exp. Psychol. 32: 3-25.

Posner, M.I. and S.E. Petersen. 1990. The attention system of the human brain. Ann. Rev. Neurosci. 13: 25-42.

Posner, M.I., T.S. Early, E. Reiman, P.J. Pardo, and M. Dhawan. 1988. Asymmetries in hemispheric control of attention in schizophrenia. Arch. Gen. Psychiatry 45: $814-821$.

Posner, M.I., J.A. Walker, F.J. Friedrich, and R.D. Rafal. 1984. Effects of parietal injury on covert orienting of attention. J. Neurosci. 4: 1863-1874.

Rafal, R.D., M.I. Posner, J.H. Friedman, A.W. Inhoff, and E. Bernstein. 1988. Orienting of visual attention in progressive supranuclear palsy. Brain 111: 267-280.

Raichle, M.E., J.A. Fiez, T.O. Videen, A.M. MacLeod, J.V. Pardo, P.T. Fox, and S.E. Petersen. 1994. Practice-related changes in human brain functional anatomy during nonmotor learning. Cereb. Cortex 4: 8-26.

Robertson, L.C., R.T. Knight, R. Rafal, and A.P. Shimamura.

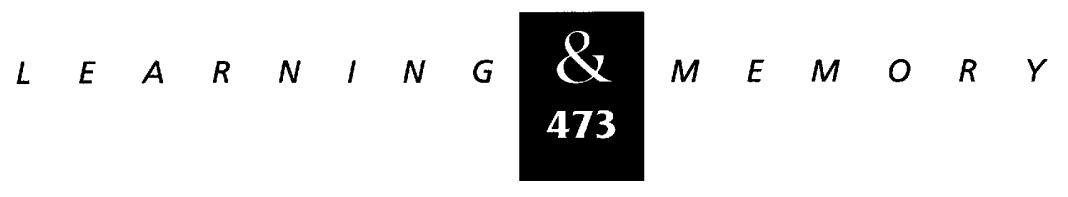




\section{Helmuth et al.}

1993. Cognitive neuropsychology is more than single-case studies. J. Exp. Psychol. Learn. Mem. Cognition 19: 710-717.

Roland, P.E., B. Larsen, N.A. Lassen, and E. Skinhoj. 1980. Supplementary motor area and other cortical areas in organization of voluntary movements in man. J. Neurophysiol. 43: 118-136.

Ryding, E., J. Decety, H. Sjoholm, G. Stenberg, and D.H. Ingvar. 1993. Motor imagery activates the cerebellum regionally. A SPECT rCBF study with 99mTc-HMPAO. Cognitive Brain Res. 1: 94-99.

Schmahmann, J.D. 1996. From movement to thought: Anatomic substrates of the cerebellar contribution to cognitive processing. Hum. Brain Mapping 4: 174-198.

Spidalieri, G., L. Busby, and Y. Lamarre. 1983. Fast ballistic arm movements triggered by visual, auditory, and somesthetic stimuli in the monkey. II. Effects of unilateral dentate lesion on discharge of precentral cortical neurons and reaction time. J. Neurophysiol. 50: 1359-1379.

Townsend, J. and E. Courchesne. 1994. Parietal damage and narrow "spotlight" spatial attention. J. Cognit. Neurosci. 6: $220-232$.

Townsend, J., E. Courchesne, and B. Egaas. 1996a. Slowed orienting of covert visual-spatial attention in autism: Specific deficits associated with cerebellar and parietal abnormality. Dev. Psychopathol. 8: 563-584.

Townsend, J., N.S. Harris, and E. Courchesne. 1996b. Visual attention abnormalities in autism: Delayed orienting to location. J. Int. Neuropsychol. Soc. 2: 541-550.

Received February 27, 1997; accepted in revised form April 22, 1997. 


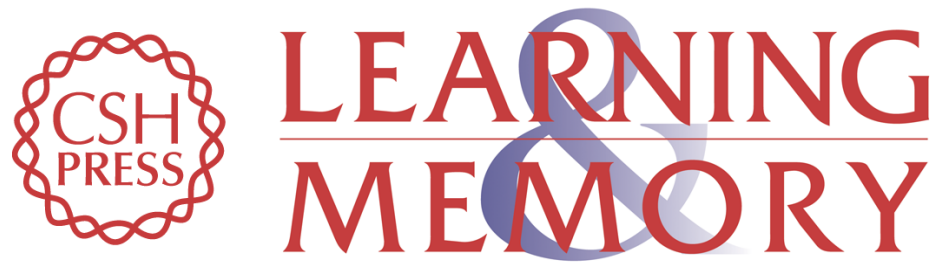

\section{Preserved performance by cerebellar patients on tests of word generation, discrimination learning, and attention.}

L L Helmuth, R B Ivry and N Shimizu

Learn. Mem. 1997, 3:

Access the most recent version at doi:10.1101//m.3.6.456

References This article cites 48 articles, 8 of which can be accessed free at: http://learnmem.cshlp.org/content/3/6/456.full.html\#ref-list-1

License

Email Alerting Receive free email alerts when new articles cite this article - sign up in the box at the Service top right corner of the article or click here. 